d- $\mathrm{Al}_{2} \mathrm{O}_{3}$ ガラス組成からなるコルハート粒を $\mathrm{O}_{2}, \mathrm{~N}_{2}$, CO ガス中で $1300^{\circ} \mathrm{C}$ まで加熱したときに抢てる粒中の $\alpha-\mathrm{Al}_{2} \mathrm{O}_{3}$ 格子の変化とか変色について実験し, まずコル ハート中コランダム粒の加熱性状を検討した。

結果を要約すると次の通りである。

1）コルハート粒から抽出した $\alpha-\mathrm{Al}_{2} \mathrm{O}_{3}$ 粒単味を $\mathrm{O}_{2}$ 中で加熱したときには $\mathrm{N}_{2}, \mathrm{CO}$ ガス中での加熱とくらべ て僅が $a_{030}$ が小さくなったが，化学分析から，乙の 原因を確めた結果， $\mathrm{Fe}^{3+}$ の還元よりも $\mathrm{Ti}^{3+}$ の酸化の 影響であろう。

2）コルハートからガラス成分を除去したムライト， $\alpha-\mathrm{Al}_{2} \mathrm{O}_{3}$ の結晶混合物からなる粒とコルハート粒を加熱 したときの粒中の $\alpha-\mathrm{Al}_{2} \mathrm{O}_{3}$ の $a_{030}$ の変化は $\alpha-\mathrm{Al}_{2} \mathrm{O}_{3}$ 単味の粒を加熱したときとは違った変化をおてす。すな わち, $\mathrm{O}_{2}, \mathrm{~N}_{2}$ 中では加熱温度の上昇にともなって $a_{003}$ が小さくなるが， $\mathrm{CO}$ 中では， $a_{030}$ は $1300^{\circ} \mathrm{C}$ 亿加熱し た場合よりも $1100^{\circ} \mathrm{C}$ の加熱で小さくなる，粒中のムう イトの $c_{002}$ の変化も $a_{030}$ と同様の傾向を示した. との
傾向は色調，化学分析からもわかる。還元気中で固溶不 純物を析出する温度は比較的低温度でおてる。乙れは共 存物質と還元気による影響であろう。

終りに，本研究について終始御激励々御指導を賜った名古屋 大学工学部応用化学教室の野田稲吉教授に厚くお礼定申乙上げ ます。

$$
\text { 文献 }
$$

1）堀部・桑原，工化，63，2107 (1960)。

2) 林武志, 酎火物, 64, 272 (1962).

3) M.G. Schrewelius, J. Am, Ceram. Soc., 31, 170 (1948).

4) W.D. Mc Kee and E. Aleshin, J. Am. Ceram. Soc., 46 [1] 54 (1963).

5）山口悟郎“日本物理学会主催，X 線廻折法講習会テキス ト” p. 163 (1958).

6）永広，御代，旭硝子研報，5［2]136（1955）.

7）山口悟郎, 窒協, 70 [8] C 333 (1962).

8) M.R. Murthy and F.A. Hummel, J. Am. Ceram, Soc., 43 [5] 267 (1950).

9）永広，御代，旭硝子研報，4[2]133（1954）。

(7/20/64 受付)

\title{
常圧蒸留法による砒素-硫黄缶板状ガラスの直接生成
}

\author{
田中雅美・向井修・上池修 \\ (大阪府立大学工学部)
}

\section{Direct Formation in Sheet Form of Arsenic-Sulfur Glasses by Distillation under Normal Pressure}

\author{
By \\ Masami TANAKA, Osamu MUKAI and Osamu KAMIIKE \\ (Dept. of Applied Chem., University of Osaka Prefecture, Sakai, Osaka)
}

\begin{abstract}
An apparatus of a laboratory scale was constructed for the direct formation in sheet form of arsenic-sulfur glasses by the distillation of raw glass batches under normal pressure. The present apparatus comprises a vertical distillation chamber, a batch container kept in the chamber, and a condensate depositer attached at the bottom of the chamber. The following materials are easily available for making the distillation chamber, batch container and condensate depositer : silica glass, 96\% silica glass and glazed porcelain. Aluminum metal is especially recommended as a material of the condensate depositer with good temperature uniformity. By modifying the inner shape of the condensate depositer, arsenic-sulfur glasses can be directly formed in shapes of disk, square plate, circular and square rods, wedge, hemisphere, prism, and so on.

The optimum temperature condition of operating the above apparatus for the direct formation of transparent arsenic-sulfur glasses was as follows : $470^{\circ} \sim 550^{\circ} \mathrm{C}$. for the temperature of batch container; $330^{\circ} \sim 430^{\circ} \mathrm{C}$. for that of condensate depositer. The X-ray diffraction measurements on transparent sheets condensed under the above optimum temperature condition of distillation and on their crushed powders showed that these sheets were glassy.

When the batch container of about $30 \mathrm{~m} l$. capacity and about $45 \mathrm{~mm}$. diameter was used, it usually took $3 \sim 6$ hours after starting to heat the container to condense a glass disk of about $40 \mathrm{~mm}$. diameter and $3 \sim 4 \mathrm{~mm}$. thickness under the above temperature
\end{abstract}


condition of distillation. It was desirable for the condensation of a glass disk with larger diameter and thickness than the above to increase the capacity of the batch container; one of the effective methods for increasing the rate of the glass condensation was to increase the diameter of the batch container.

The composition of condensed glasses was usually within the range of about 61 weight $\% \mathrm{As}\left(\mathrm{As}_{2} \mathrm{~S}_{3.0}\right)$ to about 65 weight $\% \mathrm{As}\left(\mathrm{As}_{2} \mathrm{~S}_{2.5}\right)$ when the composition of raw glass batches was $\mathrm{As}_{2} \mathrm{~S}_{3}$ and/or $\mathrm{As}_{2} \mathrm{~S}_{3}+\mathrm{S}$ (mole ratio). The arsenic content of condensed glasses was decreased with decreasing the arsenic content of raw glass batches, and the composition of the glasses was usually within the range of about 34 weight $\%$ As $\left(\mathrm{As}_{2} \mathrm{~S}_{9.0}\right)$ to about 54 weight $\%$ As $\left(\mathrm{As}_{2} \mathrm{~S}_{4.0}\right)$ when the composition of raw glass batches was $\mathrm{As}_{2} \mathrm{~S}_{3}$ $+8 \mathrm{~S}$ (mole ratio). The arsenic content of condensed glasses was decreased with lowering the temperatures of the batch container and/or the condensate depositer when the composition of raw glass batches was kept constant.

Mixtures of arsenic and sulfur in the powder forms were also available as raw glass batches for the direct formation of arsenic-sulfur glasses; the temperature of operation in this case was nearly equal to the above case using raw glass batches of the arsenic trisulfidesulfur system.

[Received Aug. 6, 1964]

\section{I. ま がき}

砒素 (As)-硫黄 (S) 系ガラスは, 防湿絶縁用低融点 ガラス材料 ${ }^{132)}$ の基礎的組成の一つであるとともに, 赤 外線工学機器用の空, レンズ, 補正板, プリズム, およ

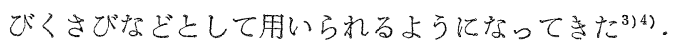

この As-S 系ガラスを透明な板状に調製するために， 蒸留によって生成させたガラス塊を再加熱によって鋳造 する操作が，Frerichs ${ }^{5}$ 亿よって報告されている。ま た，蒸留管の中でガラスバッチを加熱して融解蒸発さ せ, 輸送管や凝縮管を通して凝縮物受器内に熔融ガラス を捕集し, 最終製品に仕上げ易い形状で固化させる方式 の蒸留装置などが, U pton $^{6}$ や Jerger と Fraser ${ }^{7}$ らに よって考案された。

著者らは, 垂直型蒸留管内にバッチ容器を固定し, 蒸 留管の下端に凝縮物受器を取り付けるととによって, 装 置や加熱操作の簡易化などを図った新しい方式の小型蒸 留装置をつくり，それによって透明な As-S 系ガラスを 板状に面接生成させるための条件を検討し，ついでガう スの生成条件と組成との関係をしらべた。それらについ て報告する。

\section{II. 実 験 試 料}

\section{1. 使用原料とその配合}

As-S 系板状ガラスの直接生成に 用いた原料は, 片山化学製化学用三 硫化砒素 $\mathrm{As}_{2} \mathrm{~S}_{3}$, 同社製 “E.P.試薬” 級硫黄 $\mathrm{S}$, 同社製化学用金属砒素 As, 古河鉱業製純金属昆素As (anal) (同社分析純度 99.9999\%)，および 関東化学製保証試薬特級硫黄 S (anal).である.これらの原料を表一 1 に示した割合 (モル比) で混合し て, As-S 系ガラスのバッチとし た.'バッチ組成は，たと觉ば， $\mathrm{As}_{2} \mathrm{~S}_{3}$
と $\mathrm{S}$ とを $1: 2$ のモル比で混合したものを $\mathrm{As}_{2} \mathrm{~S}_{3}+2 \mathrm{~S}$ として表わし，との組成のバッチを O-2S の記号で示 してある、また，As と S とを $1: 3$ のモル比で混合 したものはAs+3S として表わし，ての組成のバッチ は A-3S の記号で示してある。その他の組成のバッチ も同様の表示法に従っている.

\section{2. 生成ガラス組成の決定}

常压蒸留法によって生成させた As-S 系ガラスでは, その中にバッチ中の不揮発性不純物の混入することが著 しく抑制されるので，そのガラス中の吪素を定量して組 成を定めた。乙のさいの呧素の定量は, As-S 系ガラス 試料を発煙硝酸で酸化して $\mathrm{As}_{2} \mathrm{O}_{5}$ として秤量した。そ の操作は，As-S 系膜状ガラスの常圧蒸着法についての 田中らの報文8)の中で述べた通りである。

\section{III. ガラス生成装置}

\section{1. 装置とその操作}

As-S 系板状ガラスを直接生成させる常圧蒸留装置の 形状を検討するための予備的試験によってえられた結果

Table 1. Composition of raw glass batches.

$\begin{array}{ll}\text { Notation } & \begin{array}{c}\text { Composition } \\ \text { (mole ratio }\end{array} \\ \text { O-0 } & \mathrm{As}_{2} \mathrm{~S}_{3} \\ \mathrm{O}-1 \mathrm{~S} & \mathrm{As}_{2} \mathrm{~S}_{3}+\mathrm{S} \\ \mathrm{O}-1.5 \mathrm{~S} & \mathrm{As}_{2} \mathrm{~S}_{3}+1.5 \mathrm{~S} \\ \mathrm{O}-2 \mathrm{~S} & \mathrm{As}_{2} \mathrm{~S}_{3}+2 \mathrm{~S} \\ \mathrm{O}-4 \mathrm{~S} & \mathrm{As}_{2} \mathrm{~S}_{3}+4 \mathrm{~S} \\ \mathrm{O}-8 \mathrm{~S} & \mathrm{As}_{2} \mathrm{~S}_{3}+8 \mathrm{~S} \\ \mathrm{~A}-3 \mathrm{~S} & \mathrm{As}+3 \mathrm{~S} \\ \mathrm{~A} \text { (anal)- } & \mathrm{As} \text { (anal) }+ \\ 3 \mathrm{~S} \text { (anal) } & 3 \mathrm{~S} \text { (anal) } \\ \mathrm{A} \text { (anal)- } & \mathrm{As} \text { (anal) }+ \\ 3.5 \mathrm{~S} \text { (anal) } & 3.5 \mathrm{~S} \text { (anal) }\end{array}$

*Katayama Chem. Ind. Co.'s "commercial chemicals of the highest quality" **99.9999\% chemically pure arsenic (Furukawa Kogyo Co. analyzed)

†Katayama Chem. Ind. Co.'s "E.P. reagent" grade chemicals

t†Kanto Chem. Co.'s special grade-guaranteed-reagent 


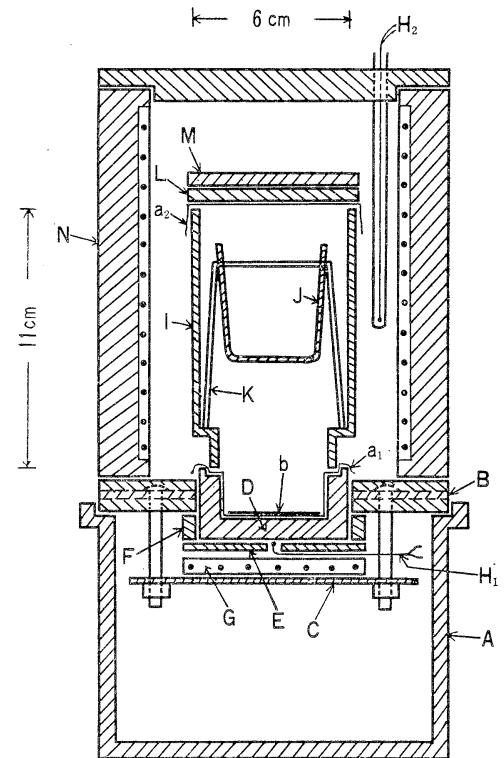

A : Furnace stand

B : Insulator clad metal plate

C : Supporter of distillator

D : Condensate depositer

$\mathrm{E}$ : Temperature equalizing sheet

$\mathrm{F}$ : Insulator segment

$\mathrm{G}$ : Temperature regulating heater for D

$\mathrm{H}_{1}, \mathrm{H}_{2}$ : Thermocouples

I : Distillation chamber

Fig. 1. Schematic diagram of a distillation apparatus.

をもとにして，図-1 に示したガラス生成装置をつくっ た。

まず，電気炉支持台 $\mathrm{A}$ の上に，断熱材で被覆した金 属板 $\mathrm{B}$ を器く、B には蒸留器支持台 C が設けられて いる. この C の上に, 凝縮物受器 $\mathrm{D}$, 均熱板 $\mathrm{E}$, 熱 電対 $\mathrm{H}_{1}$ ，断熱材七グメント $\mathrm{F}$ ，および温度調節用七一 ター $\mathrm{G}$ を，図に示されているように取り付ける。凝縮 物受器 Dの内面は, 厚さ $0.02 \mathrm{~mm}$ 程度のアルミニウ 么箔 $\mathrm{a}_{1}$ でおおい，その上に厚さ $0.15 \mathrm{~mm}$ 程度のアル ミニウム薄板 b を図に示したように置くととが望まし い。アルミニウム䈋 $\mathrm{a}_{1}$ は，凝縮したガラスが凝縮物受 器 D の内面に直接付着するのを防ぐとともに, 凝縮物 受器 $\mathrm{D}$ と蒸留管 I との接触面のパッキングとしても役 立つ。また，アルミニウム薄板 b は, 凝繀した熔融ガラ スを平板状に固化させるのに役立つものである。

次に, 凝縮物受器 D の上飞縦型蒸留管 I を置く。バ ッチ容器 Jは, 三脚台 $\mathrm{K}$ にって蒸留管 I の内部に保 持される。うわぶた L の上に，おもり $\mathrm{M}$ を置く。乙 れは, 蒸留管 $\mathrm{I}$, うわぶた $\mathrm{L}$, および凝縮物受器 D の 間の接触面の気密性を向上させるのに役立つ、なお，蒸

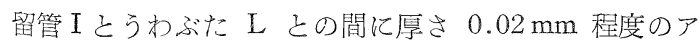
ルミニウム箔 $\mathrm{a}_{2}$ を入れることなども，蒸留管 I とうわ ぶた L との接触面に打ける気密性の向上に役立つ。熱
電対 $\mathrm{H}_{2}$ を入れた縱型電気炉 $\mathrm{N}$ は，断熱材被覆金属板 $\mathrm{B}$ 上に置く

こののち, 電気炉 $N$ によって, 蒸留管I の外側から バッチ容器 Jの中のガラスバッチを加熱する。ヒーター Gによって凝縮物受器 Dの温度が適当な範囲内に調節さ れていると, ガラスバッチからの蒝発物は凝縮物受器 D の内面に熔融ガラスとして凝縮する。

凝縮物受器 D 内に凝縮したガラスは, 蒸留操作を終 えたのち, 電気炉 $N$ 内で冷却するか, または凝縮物受 器 D を炶外に取りだして冷却する。凝縮物受器 D内 のガラスは, 冷却後, アルミニウム箔 $\mathrm{a}_{1}$ やアルミニウ ム薄板 bに付着した板状ガラスとして取りだされる。こ の板状ガラスからアルミニウム䈹 $\mathrm{a}_{1}$ やアルミニウム薄 板bを分離するための簡便な方法の一つは，そのガラス を希塩酸中に浸漬することである。それによって，アル ミニウム䇴やアルミニウム薄板は溶解し, 而塩酸性であ る As-S 系板状ガラスが残る。

容量約 $30 \mathrm{~m} l$ で口径約 $45 \mathrm{~mm}$ のバッチ容器 $\mathrm{J}$ を用 いて, 直径約 $40 \mathrm{~mm}$ で厚さ $3 \sim 4 \mathrm{~mm}$ の円板状ガラス を凝縮物受器 D 内に直接生成させるのに必要な時間 は, 次の IV 節で述べる最適蒸留温度条件のもとでは, 電気炻 N の加熱卖開始してから通常 3〜6 時間であっ た。生成する円板状ガラスの直径や厚さをさらに大きく するには, バッチ容器Jの容量をいっそう大きくするて とが望ましい。また，熔融ガラスの凝縮速度を増大させ る有効な方法の一つは, バッチ容器 J の直径を大きくす ることである．

なお，凝縮物受器 D の内部の形状を適当に変えると とによって, 砒素一硫黄系ガラスを, 円板状や角板状の ほかに，角棒状，丸棒状，〈さび状，半球状，およびプ リズム状などに直接生成させることが可能である。

\section{2. 蒸留器の材質}

蒸留管とバッチ容器の材質としては, シリカガラス, 96\% シリカガラス, 上舳付き磁器などが容易に使用で きる、凝縮物受器の材質については，アルミニウム，ま たは蒸留管やバッチ容器に使用できる前記の諸材料など は, すべて使用できる、凝縮物受器に要求される温度の 均一性の観点から,アルミニウムは凝縮物受器の材質と して特に望ましいものであるととを認めた。

\section{IV. ガラス生成条件の検討}

前節III に示した方式の蒸留装置を用い，シリカガラ 又製蒸留管の内径を約 $60 \mathrm{~mm}$ （ただし，凝綃物受器と の接触部付近での内径は約 $43 \mathrm{~mm}$ ), 長さを約 $110 \mathrm{~mm}$ とし, また上釉付き磁器質'バッチ容器の容量を 30〜 50 $\mathrm{m} l$, 口径を 28 45 mm として, 常圧蒸留法によって透 明な As-S 系板状ガラスを直接生成させるための条件 を検討した。えられた結果と結論とを次に示す。 


\section{1. 蒸留温度条件}

(1) バッチ容器の加熱温度 バッチ容器の温度 は, 硫黄の沸点 (約 $445^{\circ} \mathrm{C}$ ) より高く, 約 $600^{\circ} \mathrm{C}$ より 低く保つととが望ましい。るっとも適当な温度範 囲は $470^{\circ} \sim 550^{\circ} \mathrm{C}$ である. $550^{\circ} \mathrm{C}$ 付近よりも高い温度になる と, ガラスバッチの突沸様現象によって, 凝縮物受器内 亿生成したガラスを污濁させる場合がある。

(2) 凝縮物受器の加熱温度凝縮物受器の温度が 三硫化䂤素の融点 $\left(300^{\circ} \mathrm{C}\right)$ 付近より低いとさには, 生 成ガラスにあわやくもりの存在が一般隹認められる。乙 れは, 三硫化吡素の融点付近よりも低い温度域で凝縮し たガラスがあわを含む凝縮層を形成しやすく，また結晶 化の傾向をも示すためであろう. $300^{\circ} \sim 330^{\circ} \mathrm{C}$ の温度域 の凝縮物受器に生成したガラスには, 眽理の認められる 場合が多い。また，凝縮物受器の温度が $430^{\circ} \mathrm{C}$ 付近よ りも高くなると，生成ガラス中にあわが含まれる場合が 多くなる。乙れは，生成ガラス中の硫黄成分の揮発性と 関係しているものと考えられる。

故に，あわやにでりの見うけられない透明な As-S 系 板状ガラスを直接生成させるために望ましい凝縮物受器 の温度は, $330^{\circ} \sim 430^{\circ} \mathrm{C}$ の範囲内にある。なお, 生成ガ ラスの砒素含量が比較的多いときにはその温度範团の高 温側が，また比較的少ないときにはその温度範囲の低温 側が，凝縮物受器の最適温度域であると認められる。

（1）と（2）に示した最適蒸留温度条件のもとで生成 した $\mathrm{As}_{2} \mathrm{~S}_{3.3}$ と $\mathrm{As}_{2} \mathrm{~S}_{7.3}$ とに近い組成の薄板と, それら を砕いた粉末とについて光られたX線回折図には，結晶 による鋭いピークが見いだされず，それらの薄板がガラ ス状であるととを示している.

\section{2. ガラスの生成条件と組成との関係}

前項 1 亿示した最適蒸留温度条件のもとで, 数種の配 合比のガラスバッチから直接生成させた As-S 系板状ガ
る・なお， $\mathrm{As}_{2} \mathrm{~S}_{3}$ の組成のガラスバッチ $(\mathrm{O}-0 \mathrm{~S})$ を用 いた場合のガラスの収率は比較的小さい。

表-2 に示したガラスバッチのうちの O-8S (No. 1) 〜O-8S.(No. 4) についての結果からわかるように，バ ッチ組成が一定のときには，バッチ容器の温度または凝 縮物受器の温度が高いほぞ, 生成ガラスの砒素含量は増 大する傾向がある。また，O-8S (No. 1)，O-4 S，およ び O-2 S の 3 種のガラスバッチの 蒸留温度条件之生成 ガラス組成との比較によってわかるように，バッチ中の 吪素含量が増大するにつれて生成ガラスの䂤素含量き増 大する。そして，O-1.5 S, O-1 S, および O-0 S のガ ラスバッチの蒸留によって生成したガラスが，表-2 に 示されたガラス中でもっとも砒素含量の多いグループに 入っているが，てのととはバッチ組成と蒸留温度条件と についての上で述べた知見と一致している。

硕素粉末之硫黄粉末とを混合してえられるガラスバッ チの蒸留によっても，As-S 系ガラスを直接生成させる ととができる。その生成条件は，表-2 の中に A-3 S と $\mathrm{A}$ (anal)-3.5 S(anal) とのガラスバッチについて示した ように，三硫化砒素粉末と硫黄粉末との混合系のガラス バッチを用いる場合についてえろれた結論とほぼ同じで める。

\section{V.むすび}

（1）常压蒸留法によって透明な 砒素-硫黄系ガラス を板状に直接生成させるための新しい方式の小型装置を つくり, その操作について述べた。この常圧蒸留装置 は，垂直型蒸留管内にバッチ容器を固定し，蒸留管の下 端に凝縮物受器を取り付ける方式のものである。乙の装 置において, 凝縮物受器の内部の形状を適当に変えるて とによって, 透明な吪素一硫黄系ガラスを, 円板状や角 板状のほかに, 角棒状, 丸棒状, くさび状, 半球状, お了
ラスの組成域をまとめて，表-2 亿

示す。こてで，ガラスバッチの調合 に用いた原料は，すべて粉末状のも のである。

ての表に示されているように， $\mathrm{As}_{2} \mathrm{~S}_{3}$ または $\mathrm{As}_{2} \mathrm{~S}_{3}+\mathrm{S}$ などの組 成のガラスバッチから生成されるガ ラスの組成域は，通常 $\mathrm{As}_{2} \mathrm{~S}_{2.5}$ 〜 $\mathrm{As}_{2} \mathrm{~S}_{3.0}$ の付近である。またガラス バッチ組成が $\mathrm{As}_{2} \mathrm{~S}_{3}+1.5 \mathrm{~S}, \mathrm{As}_{2} \mathrm{~S}_{3}$ $+2 \mathrm{~S}, \mathrm{As}_{2} \mathrm{~S}_{3}+4 \mathrm{~S}$, および $\mathrm{As}_{2} \mathrm{~S}_{3}$ $+8 \mathrm{~S}$ であるとき亿生成されるガラ スの組成域は,通常それぞれ $\mathrm{As}_{2} \mathrm{~S}_{3.0}$ $\sim \mathrm{As}_{2} \mathrm{~S}_{3.5}$ の付近, $\mathrm{As}_{2} \mathrm{~S}_{3.0} \sim \mathrm{As}_{2} \mathrm{~S}_{4.0}$ の付近, $\mathrm{As}_{2} \mathrm{~S}_{4.0} \sim \mathrm{As}_{2} \mathrm{~S}_{5.0}$ の付近, および $\mathrm{As}_{2} \mathrm{~S}_{4.0} \sim \mathrm{As}_{2} \mathrm{~S}_{9.0}$ の付近であ
Table 2. Composition of directly condensed arsenic-sulfur glass sheets.

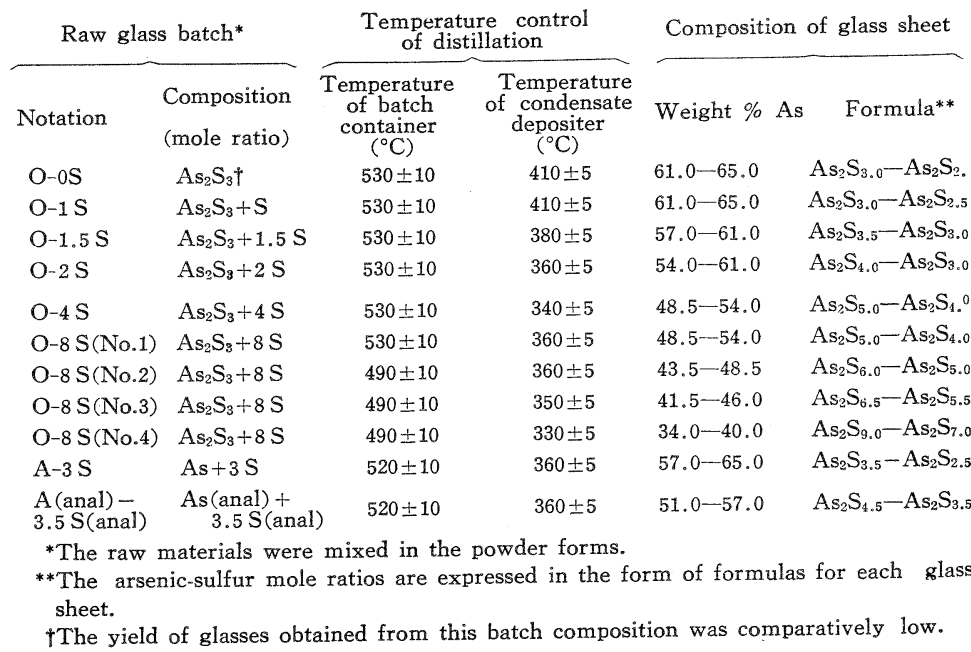


よびプリズム状などに直接生成させるととが可能であ 当。

（2）との装置による吪素-硫黄系ガラスの蒸留温度 条件の概要は次のとおりである。バッチ容器の温度は, 流黄の沸点 (約 $445^{\circ} \mathrm{C}$ ) より高く, 約 $600^{\circ} \mathrm{C}$ より低く 保つとと方望ましい。その最適温度域は $470^{\circ} \sim 550^{\circ} \mathrm{C}$ で 尚当. 凝縮物受器の適温域は $330^{\circ} \sim 430^{\circ} \mathrm{C}$ であり, 生成 ガラスの吪素合量が比較的多いとき亿法その高温側が， 比較的少ないときにはその低温側が最適温度域である。

(3) $\mathrm{As}_{2} \mathrm{~S}_{3}$ または $\mathrm{As}_{2} \mathrm{~S}_{3}+\mathrm{S}_{3}$ (モル比) の組成のガ ラスバッチから生成されるガラスの組成域は, 通常 $\mathrm{As}_{2} \mathrm{~S}_{2.5} \sim \mathrm{As}_{2} \mathrm{~S}_{3.0}$ の付近である.ガラスバッチ中の吪素 含量が減少するにつれて, 生成ガラスの䂤素含量も減少 する.そして, $\mathrm{As}_{2} \mathrm{~S}_{3}+8 \mathrm{~S}$ (モル比) の組成のガラスバ ッチから生成されるガラスの組成域は, 通常 $\mathrm{As}_{2} \mathrm{~S}_{4.0}$ 〜 $\mathrm{As}_{2} \mathrm{~S}_{9.0}$ の付近である.

（4）ガラスバッチの組成が一定のときには，バッチ 容器の温度または凝縮物受器の温度が低いほど, 生成ガ ラスの砒素含量は減少する傾向がある。

（5）砒素粉末と硫黄粉末とを混合してえられるガラ スバッチを用いても，三硫化吪素粉末と硫黄粉末との混 合系のガラスバッチを用いた場合とほぼ同じ生成条件に
よって, 砒素-硫黄系ガラスを直接生成させるととがで きる。

\section{文献}

1) S.S. Flaschen, D.A. Pearson \& W.R. Northover, J. Am. Ceram. Soc., 42 [9] 450 (1959); Id., ibid., 43 [5] 274-78 (1960).

2) W.R. Sinclair, S.S. Flaschen \& F.G. Peters, ibid, 43 [3] 168 (1960).

3）和田・中野共訳, 赤外線工学 (H.L. Hackforth, Infrared Radiation, McGraw-Hill, 1960), p. 135. 近代科学 社, 東京, 昭 $38,330 \mathrm{pp}$.

4) J.A. Jamieson et al., Infrared Physics and Engineering, p. 254, McGraw-Hill, 1963, 673 pp.

5) R. Frerichs, J. Opt. Soc. Am., 43 [12] 1153-57 (1953).

6) L.O. Upton, U.S. 2,804,378 (Aug. 27, 1957).

7) J. Jerger, Jr. \& W.A. Fraser, U.S. 2,886,491 (May 12, 1959).

8）田中・滝本・上池, 窯協, 72 [9] 164-68 (1964).

[8/6/1964 受付]

\section{ERATTA}

Vol. 72, No. 9, p. 164 の下汃引 8 行目 to $\mathrm{As}_{2} \mathrm{~S}_{3}$ は $\mathrm{As}_{2} \mathrm{~S}_{3}$ と, ircrushed は crushed とそれぞれ訂正.

Vol. 72 , No. 10，p. 178 の右段下から 10 行目 IV. 考案は IV. 考察と訂正.

\title{
$\gamma$-酸化鉄 $($ III $)$ の $\alpha$-酸化鉄 $($ III $)$ への転移の 鉱酸による促進作用
}

\author{
久保輝一郎・白 崎 信 - ・御手洗征明 \\ (東京工業大学理工学部合成化学科)
}

\section{Catalytic Action of Mineral Acids in the Transformation from $\gamma-\mathrm{Fe}_{2} \mathrm{O}_{3}$ into $\alpha-\mathrm{Fe}_{2} \mathrm{O}_{3}$}

By

\author{
Teruichiro KUBO, Shinichi SHIRASAKI and Yukuaki MITARAI \\ (Tokyo Institute of Technology)
}

The effect of various matrials added to $r-\mathrm{Fe}_{2} \mathrm{O}_{3}$ on transformation into $\alpha-\mathrm{Fe}_{2} \mathrm{O}_{3}$ was investigated by means of D.T.A., high temperature $\mathrm{X}$-ray diffraction technique and others. The promotion of transformation by addition of metallic compounds such as metal oxides and metal salts, which was widely confirmed in many other reactions taking part in solids, was hardly recognized in this study, howevever, the immersion of $\gamma-\mathrm{Fe}_{2} \mathrm{O}_{3}$ into mineral acid solutions such as hydrochloric acid and sulfuric acid solution had the remarkable effect on this transformation.

The obtained results are summarized as follows:

(1) Such a effect by the immersion of $\gamma-\mathrm{Fe}_{2} \mathrm{O}_{3}$ into hydrochloric acid and sulîuric acid solution disappeared by washing till the sample got free from chloride and sulfate ions absorbed on it. This result allows us to consider that the accelerating action for this transformation does not relate to degraded particle size of $\gamma-\mathrm{Fe}_{2} \mathrm{O}_{3}$.

(2) $r-\mathrm{Fe}_{2} \mathrm{O}_{3}$ treated with two mineral acid solutions was locally converted, especially in its surface, to $\mathrm{FeOCl}$ and hydrated $\mathrm{FeSO}_{4}$ respectively by the reaction with the mineral 